\title{
Characteristics and evolution of 38 patients with rheumatic diseases and COVID-19 under DMARD therapy
}

\author{
Dionicio Ángel Galarza-Delgado ${ }^{1}$ (D) - Griselda Serna-Peña ${ }^{1}$. Jesús Eduardo Compeán-Villegas ${ }^{1}$. \\ Jesus Alberto Cardenas-de la Garza ${ }^{1}$ • Rita Angélica Pineda-Sic ${ }^{1}$ • Iris Jazmín Colunga-Pedraza ${ }^{1}$. \\ David Vega-Morales ${ }^{1} \cdot$ Lorena Pérez-Barbosa $^{1} \cdot$ Cassandra Michelle Skinner-Taylor $^{1}$. Diana Elsa Flores-Alvarado ${ }^{1}$
}

Received: 22 September 2020 / Revised: 11 November 2020 / Accepted: 15 November 2020 / Published online: 24 November 2020

(C) International League of Associations for Rheumatology (ILAR) 2020

To date, we still have questions about the outcomes of patients with rheumatic inflammatory diseases who develop COVID19 on disease-modifying antirheumatic drugs (DMARDs) therapy; consequently, efforts to reach conclusions continue. According to the review by Ladani et al. [1], autoimmune rheumatic diseases have not been identified as a risk factor for COVID-19. In like manner, it is expected that some patients with poorly controlled disease may be at increased risk of contracting SARS-CoV-2 infection; hence, they must be encouraged to continue their usual medication. On the other hand, although some therapies used by rheumatologists could potentially confer protection or even limit the serious manifestations of SARS-CoV-2, there is insufficient evidence to establish their safety while the patient is infected [1].

In this study, we report the characteristics and evolution of 38 patients with autoimmune rheumatic diseases from an outpatient rheumatology clinic in Monterrey, Mexico, who developed SARS-CoV-2 infection while on immunosuppressive therapy during July and August 2020.

Most of the patients were female $(n=33,86.84 \%)$ and the mean age was 43.47 years (SD 14.58). The most frequent diagnosis was rheumatoid arthritis (RA) with 15 patients (39.47\%), followed by systemic lupus erythematosus (SLE) with 13 (34.21\%), spondylarthritis with 4 (8.5\%), psoriatic arthritis with 3 (6.9\%), and systemic sclerosis, Sjogren's syndrome, and systemic vasculitis with one patient each. Diagnosis of COVID-19 was confirmed by reverse

Dionicio Ángel Galarza-Delgado

dgalarza@medicinauanl.mx

1 Servicio de Reumatología, Hospital Universitario, Universidad Autónoma de Nuevo León, Av. Gonzalitos No. 235 Nte. Col. Mitras Centro, C.P. 64460 Monterrey, NL, México transcription polymerase chain reaction (RT-PCR) in all patients. Regarding immunosuppressive therapy, 29 patients were treated with csDMARDs $(76.31 \%)$, eleven with bDMARDs $(28.94 \%)$, and $3(7.89 \%)$ with tsDMARDs (Table 1).

Most of the patients developed mild COVID-19, defined as no requirement of hospitalization or oxygen ( $n=31,81.57 \%)$; five $(13.15 \%)$ developed moderate disease (need of hospitalization) of which 3 (7.89\%) of them required supplemental oxygen; and two patients (5.26\%) had severe COVID-19 (mechanical ventilation or death). None of the patients was treated with antiviral therapy. Among the treatments widely used in Mexico, seventeen patients $(44.73 \%)$ were treated with azithromycin, and $6(15.78 \%)$ with ivermectin. Sixteen patients $(42.60 \%)$ continued their usual treatment after acquiring the infection.

One patient underwent orotracheal intubation (a 30-yearold woman with SLE and obesity under treatment with antimalarials, methotrexate, and corticosteroids), and 1 patient died (65-year-old woman with RA and obesity under treatment with rituximab and leflunomide). The patient who died was the only one in the biologic therapy group that evolved to severe COVID-19. It is important to remark that she had other risk factors for severe COVID-19 including obesity and age. Nonetheless, B-cell depleting therapies like rituximab may be associated to worst outcomes although data is still limited to firmly conclude this [2].

Messina et al. [3, 4] reported the potential benefit of inhibition of the IL-23/IL-17 axis in COVID-19, perhaps preventing the "cytokine storm" which may lead to multiorgan failure and death. In our report, the two patients treated with IL-17 inhibitors (a 35-year-old woman with spondylarthritis treated with secukinumab and a 43-year-old man with psoriatic arthritis with ixekizumab) had a benign evolution of COVID-19. Notably, none of them had comorbidities. The number of patients reported so far receiving 
Table 1 Baseline characteristics of COVID-19 patients

\begin{tabular}{|c|c|c|c|c|}
\hline & All patients & Mild COVID-19 & Moderate COVID-19 & Severe COVID-19 \\
\hline Number of patients & 38 & 31 & 5 & 2 \\
\hline Sex, female, $n(\%)$ & $33(86.84)$ & $26(83.87)$ & $5(100)$ & $2(100)$ \\
\hline Age at COVID-19 onset, median (range) & $43.47(20-82)$ & $42.74(20-82)$ & $46.40(30-64)$ & $47.5(30-65)$ \\
\hline \multicolumn{5}{|l|}{ Rheumatic disease } \\
\hline Rheumatoid arthritis, $n(\%)$ & $15(39.47)$ & $12(38.70)$ & $2(40)$ & $1(50)$ \\
\hline Systemic lupus erythematosus, $n(\%)$ & $13(34.21)$ & $9(29.03)$ & $3(60)$ & $1(50)$ \\
\hline Psoriatic arthritis, $n(\%)$ & $3(7.89)$ & $3(9.67)$ & 0 & 0 \\
\hline Systemic sclerosis, $n(\%)$ & $1(2.63)$ & $1(3.22)$ & 0 & 0 \\
\hline Ankylosing spondylitis, $n(\%)$ & $4(10.52)$ & $4(12.90)$ & 0 & 0 \\
\hline Systemic vasculitis, $n(\%)$ & $1(2.63)$ & $1(3.22)$ & 0 & 0 \\
\hline Sjögren's syndrome, $n(\%)$ & $1(2.63)$ & $1(3.22)$ & 0 & 0 \\
\hline \multicolumn{5}{|l|}{ Comorbidities and risk factors } \\
\hline Diabetes, $n(\%)$ & $2(5.26)$ & $2(6.45)$ & 0 & 0 \\
\hline Hypertension, $n(\%)$ & $8(21.05)$ & $8(25.80)$ & 0 & 0 \\
\hline Overweight/obesity, $n(\%)$ & $17(44.73)$ & $12(38.70)$ & $3(60)$ & $2(100)$ \\
\hline Heart failure, $n(\%)$ & $1(2.63)$ & $1(3.22)$ & 0 & 0 \\
\hline Smoking, $n(\%)$ & $1(2.63)$ & $1(3.22)$ & 0 & 0 \\
\hline Corticosteroids, $n(\%)$ & $17(44.73)$ & $11(35.48)$ & $4(80)$ & $2(100)$ \\
\hline \multicolumn{5}{|l|}{ csDMARDs } \\
\hline Hydroxichloroquine, $n(\%)$ & $16(42.60)$ & $13(41.93)$ & $2(40)$ & $1(50)$ \\
\hline Metothrexate, $n(\%)$ & $15(39.47)$ & $10(32.25)$ & $4(80)$ & $1(50)$ \\
\hline Sulfasalazine, $n(\%)$ & $4(10.52)$ & $4(12.90)$ & 0 & 0 \\
\hline Leflunomide, $n(\%)$ & $6(15.78)$ & $5(16.12)$ & 0 & $1(50)$ \\
\hline Azathioprine, $n(\%)$ & 0 & 0 & 0 & 0 \\
\hline Mycophenolate, $n(\%)$ & $3(7.89)$ & $3(9.67)$ & 0 & 0 \\
\hline Cyclophosphamide, $n(\%)$ & 0 & 0 & 0 & 0 \\
\hline \multicolumn{5}{|l|}{ tsDMARDs } \\
\hline Baricitinib, $n(\%)$ & $2(5.26)$ & $2(6.45)$ & 0 & 0 \\
\hline Tofacitinib, $n(\%)$ & $1(2.63)$ & 0 & $1(20)$ & 0 \\
\hline \multicolumn{5}{|l|}{ bDMARDs } \\
\hline Anti-TNF, $n(\%)$ & $6(15.78)$ & $6(19.35)$ & 0 & 0 \\
\hline Tocilizumab, $n(\%)$ & $1(2.63)$ & $1(3.22)$ & 0 & 0 \\
\hline Ixekizumab, $n(\%)$ & $1(2.63)$ & $1(3.22)$ & 0 & 0 \\
\hline Secukinumab, $n(\%)$ & $1(2.63)$ & $1(3.22)$ & 0 & 0 \\
\hline Abatacept, $n(\%)$ & $1(2.63)$ & 0 & $1(20)$ & 0 \\
\hline Rituximab, $n(\%)$ & $1(2.63)$ & 0 & 0 & $1(50)$ \\
\hline Monotherapy of csDMARDs & $5(13.15)$ & $5(16.12)$ & 0 & 0 \\
\hline Monotherapy of tsDMARDs & $2(5.26)$ & $2(6.45)$ & 0 & 0 \\
\hline Combination of csDMARDs and bDMARDs/tsDMARDs, $n(\%)$ & $3(7.89)$ & $1(3.22)$ & $1(20)$ & $1(50)$ \\
\hline \multicolumn{5}{|l|}{ Other medications } \\
\hline ACEi, $n(\%)$ & $4(10.52)$ & $4(12.90)$ & 0 & 0 \\
\hline $\mathrm{ARB}, n(\%)$ & $4(10.52)$ & $4(12.90)$ & 0 & 0 \\
\hline NSAIDs, $n(\%)$ & $18(47.36)$ & $13(41.93)$ & $4(80)$ & $1(50)$ \\
\hline Celecoxib, $n(\%)$ & $6(15.78)$ & $5(16.12)$ & $1(20)$ & 0 \\
\hline \multicolumn{5}{|l|}{ Treatment for COVID-19 } \\
\hline Azithromycin, $n(\%)$ & $17(44.73)$ & $12(38.70)$ & $4(80)$ & $1(50)$ \\
\hline Ivermectin, $n(\%)$ & $6(15.78)$ & $6(19.35)$ & 0 & 0 \\
\hline Dexamethasone, $n(\%)$ & $7(18.42)$ & $2(6.45)$ & $4(80)$ & $1(50)$ \\
\hline Convalescent plasma, $n(\%)$ & $1(2.63)$ & 0 & $1(20)$ & 0 \\
\hline
\end{tabular}

$A C E i$ angiotensin-converting-enzyme inhibitors, $A R B s$ angiotensin II receptor blockers, $b D M A R D s$ biologic disease-modifying antirheumatic drugs, csDMARDs conventional synthetic disease-modifying antirheumatic drugs, NSAIDs nonsteroidal anti-inflammatory drugs, $R T$ - $P C R$ reverse transcription polymerase chain reaction, $t s D M A R D s$ targeted synthetic disease-modifying antirheumatic drugs

inhibitors of the IL-23/IL-17 signaling axis is too few to draw solid conclusions as many factors including comorbidities, age, and other treatments influence the evolution of COVID-19.
According to Gianfrancesco et al. [5], it was suggested that the use of anti-TNF therapy could influence a lower incidence of hospitalization. In our population, all patients with antiTNF therapy had mild disease. 
Compared to a general population study from southeastern Europe [6], we had more hospitalized patients receiving steroids; however, similar recovery rates were obtained $(85.71$ vs. $87.7 \%$ ). This highlights the role of steroids as a treatment for SARS-CoV-2 infection in patients with exaggerated immune responses [7].

Our results are similar to those reported by Duret et al. [8] and the use of DMARDs does not seem to contribute to an unfavorable evolution of COVID-19. Rheumatologists however should pay special attention to the use of rituximab as, due to its distinct mechanism of action, may be associated to complications and a worse outcome in SARS-CoV-2 infection. Limitations of our present report include the singlecenter design and the limited number of patients. As evidence continues to accumulate, the impact of different DMARDs in the evolution of COVID-19 starts to become clearer.

Contributors DAGD, GSP, and JACDG provided the idea and performed the study design. GSP, JECV, RAPS, and JACDG performed the data analysis, interpretation, and drafting of the manuscript. All the authors helped in data acquisition and revised the manuscript for important intellectual content. All authors critically revised and approved the final version of the manuscript.

Data sharing statement Additional data will be shared if needed by the corresponding author by e-mail.

\section{Compliance with ethical standards}

Disclosures None.

Ethical approval information This study was approved by Institutional board on research ethics, Hospital Universitario "Dr. José Eleuterio González," approval number RE20-00008.

Patient and public involvement statement Patients or the public was not involved in the design, or conduct, or reporting, or dissemination plans of our research.

\section{References}

1. Ladani AP, Loganathan M, Danve A (2020) Managing rheumatic diseases during COVID-19. Clin Rheumatol. 39(11):3245-3254. https://doi.org/10.1007/s10067-020-05387-8

2. Schulze-Koops H, Krueger K, Vallbracht I et al (2020) Increased risk for severe COVID-19 in patients with inflammatory rheumatic diseases treated with rituximab. Ann Rheum Dis. https://doi.org/10. 1136/annrheumdis-2020-218075

3. Messina F, Pampaloni F, Piaserico S (2020, 2020) Comment on: recovery from COVID-19 in a patient with spondyloarthritis treated with TNF-alpha inhibitor etanercept. A report on a patient with COVID-19 with psoriatic arthritis receiving ustekinumab. Ann Rheum Dis. https://doi.org/10.1136/annrheumdis-2020-218029

4. Messina F, Piaserico S (2020) SARS-CoV-2 infection in a psoriatic patient treated with IL-23 inhibitor. J Eur Acad Dermatol Venereol 34(6):e254-e255. 1-2. https://doi.org/10.1111/jdv.16468

5. Gianfrancesco M, Hyrich KL, Al-Adely S et al (2020) Characteristics associated with hospitalisation for COVID-19 in people with rheumatic disease: data from the COVID-19 Global Rheumatology Alliance physician-reported registry. Ann Rheum Dis. 79(7):859-866. https://doi.org/10.1136/annrheumdis-2020217871

6. Popov GT, Baymakova M, Vaseva V et al (2020, 2020) Clinical characteristics of hospitalized patients with COVID-19 in Sofia, Bulgaria. Vector Borne Zoonotic Dis. https://doi.org/10.1089/vbz. 2020.2679

7. Galluccio F, Ergonenc T, Garcia-Martos A et al (2020) Treatment algorithm for COVID-19: a multidisciplinary point of view. Clin Rheumatol 39(7):2077-2084. https://doi.org/10.1007/s10067-02005179-0

8. Duret PM, Spielmann L, Messer L $(2020,2020)$ Rheumatic diseases and COVID-19: a cohort of 17 patients under DMARDs. Response to: Comment on: Recovery from COVID-19 in a patient with spondyloarthritis treated with TNF-alpha inhibitor etanercept. A report on a COVID-19 patient with psoriatic arthritis receiving ustekinumab by Messina et al. Ann Rheum Dis. https://doi.org/10. 1136/annrheumdis-2020-218147

Publisher's note Springer Nature remains neutral with regard to jurisdictional claims in published maps and institutional affiliations. 